\title{
Ambientes virtuais e mídias de comunicação, abordando a explosão das mídias na sociedade da informação e seu impacto na aprendiza- gem - o uso do WhatsApp como plataforma de m-learning
}

Virtual environments and communication media, addressing explosion media in the information society and its impact on learning - the WhatsApp use as m-learning platform

Paulo Cesar Pereira ${ }^{1}$, Rafael Silva Pereira ${ }^{1}$, Jesimar da Cruz Alves ${ }^{2}$.

\begin{abstract}
Resumo
Este trabalho tem como objetivo verificar o atual uso e desenvolvimento das plataformas denominadas $m$-learning, suas vantagens e desafios a serem enfrentados para a sua disseminação na educação à distância. Descreve brevemente a evolução dos ambientes de aprendizagem através do uso das Tecnologias de Informação e Comunicação e avalia a possibilidade de utilização da tecnologia de computação móvel no auxílio ao processo de aprendizagem. O trabalho foi realizado através de pesquisa exploratória, de campo e bibliográfica, consistindo no levantamento do conhecimento bibliográfico disponível em produções atuais e no levantamento das percepções de professores de diversos níveis de formação, vinculação, tempo de docência e idades a respeito do uso de ambientes de $m$-Learning, em especial o Wattsapp. Por meio do desenvolvimento do presente estudo, foi possível observar que o uso do m-learning ainda está em fase embrionária no contexto brasileiro, mas o uso de dispositivos móveis na educação é algo que não deve ser ignorado ou pensado como improvável em pouco tempo, pois atualmente, alunos e professores buscam a interação pessoal, entre si, permitida por esta tecnologia, muito além de ser somente um distribuidor de conteúdos educacionais. Palavras-Chave: Educação. Educação à Distância. M-learning.
\end{abstract}

Como citar esse artigo. Pereira PC, Pereira RS, Alvez JC. Ambientes abordando a explosão das mídias na sociedade da informação e seu impacto na aprendizagem - o uso do WhatsApp como plataforma de m-learning. Revista Mosaico. 2015 Jan./Jun.; 06 (1): 29-41.

\begin{abstract}
This study aims to determine the current use and development of platforms called m-learning, its advantages and challenges to be faced to its spread in distance education. Briefly describes the evolution of learning environments through the use of Information and Communication Technologies and evaluates the possibility of using mobile computing technology to aid the learning process. The work was performed by exploratory research, field and literature, consisting in the survey of bibliographic knowledge available on current productions and the survey of the perceptions of teachers from different levels of training, linking, teaching experience and age on the use environments m-Learning, especially Wattsapp. Through the development of this study, it was observed that the m-learning usage is still in its infancy in the Brazilian context, but the use of mobile devices in education is something that should not be ignored or thought of as unlikely soon, because currently, students and teachers seek personal interaction with each other, permitted by this technology far beyond being just a distributor of educational content. Keywords: Education. Distance Learning. M-learning.
\end{abstract}

\section{Introdução}

Nada transforma mais as pessoas e a sociedade do que a Educação. Ela é o que nos tira da escuridão da ignorância e traz a luz do conhecimento, permitindo que possamos entender o mundo que nos cerca.

Durkheim (1973) pregava que a educação é considerada como fato social, pois se impõe, coercitivamente, como uma norma jurídica ou como uma lei. É através dela que as crianças e os jovens absorvem maneiras de ver, de sentir e de agir tornandose indivíduos integrados com uma forte identificação com o sistema social.
A prática do ser social percorre diversos espaços como a família, o clube, as associações e principalmente a escola. Durkheim acreditava que a sociedade seria mais beneficiada pelo processo educativo. Para ele, "a educação é uma socialização da jovem geração pela geração adulta". E quanto mais eficiente for o processo, melhor será o desenvolvimento da comunidade em que a escola esteja inserida. "A construção do ser social, feita em boa parte pela educação, é a assimilação pelo indivíduo de uma série de normas e princípios - sejam morais, religiosos, éticos ou de comportamento - que baliza a conduta do indivíduo num grupo. O homem, mais do que formador da sociedade, é um produto dela", escreveu Durkheim.

1. Universidade Severino Sombra/ Curso Superior em Gestão Pública.

2. Universidade Severino Sombra/Professor do Curso Superior em Administração, Pedagogia e Engenharia de Produção. 
A partir do advento da atual sociedade da informação, fomentada pelo desenvolvimento e democratização das tecnologias de informação, que ocorre de forma massiva nos últimos anos, não se pode pensar em manter o modelo tradicional da educação, sob a pena de cair no anacronismo frente as novas tecnologias.

A tecnologia de comunicação instantânea, mediada pelos aparelhos celulares e smartphones, mudou completamente a forma das pessoas se comunicarem e relacionarem-se, e os educadores não podem deixar de considerar esses equipamentos como possíveis de serem usados no processo educacional, em especial como integrador entre os atores envolvidos.

Este trabalho foi realizado parcialmente em grupo, no que tange o texto dos pressupostos teóricos e da pesquisa de campo, de forma que os mesmos serão encontrados de forma similar nos TFC's dos demais integrantes do grupo ao qual fiz parte, e aborda o uso do aplicativo Waths App, utilizado em smartphones, como possível ferramenta educacional, tentando identificar a sua penetração entre professores e seu uso potencial de uso.

As tecnologias de informação evoluem em uma velocidade muito grande, e é preciso que antes que sejam suplantadas em seu potencial de comunicação sejam avaliadas como ferramenta educacional. A evolução dos ambientes de aprendizagem através do uso das Tecnologias de Informação e Comunicação (TICs), sobretudo a Web, proporcionou mudanças significativas na forma como os materiais envolvidos no processo de ensino aprendizagem são utilizados.

A definição do tema "Ambientes Virtuais e Mídias de Comunicação, abordando a Explosão das mídias na sociedade da informação e seu impacto na aprendizagem - O uso do WhatsApp como plataforma de M-learning" para o trabalho de final de curso se deu pelo entendimento do grupo da importância das plataformas denominadas m-learning, suas vantagens e desafios a serem enfrentados para a sua disseminação na Educação à distância. Reunindo os dispositivos computacionais com a comunicação móvel celular obtém-se a computação móvel que permite a um aluno acessar conteúdos e interagir com professores e colegas estando estes em qualquer lugar, fortalecendo assim, o aprendizado móvel.

Brantes (2012), citando (Goh e Kinshuk, 2004; Hsu, 2006) "as mais recentes tecnologias móveis e sem fio (como telefones celulares, smartphones, tablets, notebooks) oferecem um conjunto de possibilidades para a aprendizagem. Elas permitem trocar informações, compartilhar ideias, experiências, resolver dúvidas, acessar uma vasta gama de recursos e materiais didáticos, incluindo texto, imagens, áudio, vídeo, e-books, artigos, notícias online, conteúdos de blogs, microblogs e jogos no exato momento em que se faz necessário. Por causa do potencial de uso generalizado desses dispositivos móveis, argumenta-se que o mobile learning (M-learning) seja a próxima onda dentre os novos ambientes de aprendizagem".

Para Pelissoli (2004), "a possibilidade de utilização da tecnologia de computação móvel no auxílio ao processo de aprendizagem, permitirá ao aluno acessar em qualquer lugar e em qualquer hora o vasto volume de informação necessário para o acompanhamento de cursos, principalmente aproveitando os horários de espera ou de locomoção".

Totti (2011) aponta que "com avanço os dispositivos móveis, eles representam um caminho alternativo para a educação, mas não em direção contrária aos já existentes", e o comprometimento do educador deve estar voltado também a identificar novas mídias, que possam ser usadas em educação. Após identifica-las, avalia-las, conhecer seu potencial e a partir destas descobertas, propor método de uso que dinamize suas vantagens e reduza suas dificuldades. Como exemplo destas alternativas cita-se o wattsapp, pela sua portabilidade e a pouca necessidade de rede de banda larga.

A grande quantidade de ferramentas móveis facilitou a disseminação do uso do WhatsApp, ferramenta gratuita e de fácil utilização, que facilitou a introdução do aplicativo como ferramenta de ensino e que pode ser utilizado como auxilio a prática docente permitindo a troca de informações entre alunos/alunos e alunos/professor em sala de aula, tanto em EAD quanto no ensino presencial.

Sendo assim, a colaboração e a interação no processo ensino-aprendizagem que tais recursos podem proporcionar é de suma importância para nosso estudo.

O objetivo deste estudo é verificar o atual uso e desenvolvimento das plataformas denominadas m-learning, suas vantagens e desafios a serem enfrentados para a sua disseminação na Educação à distância. Adicionalmente pretendeu discutir o atual uso das ferramentas de m-learning, em especial o wattsapp, as formas de sua utilização como ferramenta de interação entre alunos, distribuição de conteúdo e interação com os professores, verificar a importância das ferramentas utilizadas em m-learning, suas características de interatividade e cooperação entre alunos e tutores, e ressaltar a gratuidade das mesmas e a colaboração para uma educação mais democrática e de qualidade e analisar a realidade e o desenvolvimento da docência à distância frente às novas possibilidades tecnológicas do m-learning, suas ferramentas gratuitas, sua aplicabilidade e prática nos Ambientes Virtuais;

Este trabalho foi desenvolvido a partir de duas vertentes, a primeira originada de uma pesquisa bibliográfica, pautada a partir de produções atuais sobre o planejamento, implementação e gestão da EAD, apontando seu estado atual, suas potencialidades e 
limitações; da literatura relativa aos ambientes virtuais e mídias de comunicação; da literatura relativa ao estado atual da m-learning e Educação a distância mediada em plataformas móveis.

Segundo Macedo (1994, p.13) "pesquisa bibliográfica é a busca de informações bibliográficas, seleção de documentos que se relacionam com o problema de pesquisa (livros, verbetes de enciclopédia, artigos de revistas, trabalho de congressos, etc) e o respectivo fichamento das referências, para que sejam posteriormente utilizadas na identificação de material referencial ou na bibliografia final) ". Desta forma, buscamos artigos que descrevem experiências em educação obtidas através do m-learning, suas vantagens, desafios, a importância dessas ferramentas na disseminação da Educação à distância. Foi destinado um espaço para uma ênfase maior no emprego do aplicativo WhatsApp, atualmente muito utilizado como ferramenta de interação entre alunos e professores, em função da sua rápida disseminação entre a sociedade e a expansão do acesso à internet móvel.

O trabalho foi dividido em três temas principais: A Educação à Distância (EAD), m-learning e Uso do WhatsApp e será realizada uma pesquisa com 65 professores através de formulário Google Docs, no qual serão questionados sobre conhecer m-learning, se fazem uso, se o veem como perspectiva de futuro. A amostra é composta de professores pertencentes ás redes sociais dos pesquisadores, selecionados de maneira aleatória, a fim de manter a heterogeneidade da mesma. Nos resultados serão consolidados a percepção dos professores e comparação com a bibliografia.

A segunda vertente foi composta por uma pesquisa de campo, utilizando formulário eletrônico para a coleta de dados, com o serviço da Google. A metodologia do tipo survey, segundo Gil (2010) é "um levantamento de dados em uma amostra significativa acerca de um problema a ser estudado para, em seguida, mediante análises, obter-se as conclusões correspondentes aos dados coletados". Esta foi conduzida com a distribuição digital de formulário com questões atinentes ao uso do wattsapp na educação, e informações sobre os docentes utilizadores, de maio e julho de 2015, com 65 (sessenta e cinco) professores, independente de nível de atuação, idade, gênero ou tipo de vínculo profissional. Pretendese ao final tabular os dados e analisa-los a partir das frequências simples das respostas obtidas.

\section{Pressupostos teóricos}

Há no mundo mais de 3.200 milhões de usuários de dispositivos móveis, o que faz que esta seja a modalidade de TIC mais utilizada no planeta (Unesco, 2013) e segundo Oliveira (2014), atualmente cerca de 43 milhões de brasileiros acessam a Internet por dispositivos móveis. E destes, mais da metade são de indivíduos com idade entre 12 e 34 anos, o que evidencia que boa parte destes usuários estão inseridos no ensino básico, secundário ou superior.

Os celulares estão se tornando cada vez mais populares e seus usuários brasileiros estão passando, rapidamente, dos serviços de voz para os de dados, com acesso à Internet. Isso proporciona diversas possibilidades de uso, desde as socialmente emancipadoras até as criminais". (Pellanda, 2009).

É facilmente perceptível que cada vez mais "as tecnologias móveis atualmente estão presentes até mesmo em áreas onde escolas, livros e computadores são escassos". (Unesco, 2013).

Vivemos a sociedade da informação e "as tecnologias sem fio estão transformando as relações entre pessoas e espaços urbanos, criando novas formas de mobilidade. A tendência é que as cidades sejam cada vez mais incluídas na era da computação ubíqua, a partir das diversas tecnologias móveis. Essas metrópoles estão se tornando ambientes generalizados de conexão, envolvendo o usuário em plena mobilidade, interligando máquinas, pessoas e objetos urbanos". (Lemos, 2010). E da mesma forma, para Santaella (2008), "as tecnologias da mobilidade potencializam mudanças no modo como as pessoas percebem e interagem com o espaço, o tempo e o outro".

Pellanda (2009), considera o paradoxo que ocorre no Brasil, em que parte da população vive em condições socioeconômicas muito baixas, mas é uma das nações a adotar mais fortemente novas tecnologias, sendo expressivo o aumento de conexões resultantes da tecnologia móvel e que esta tem proporcionado diferentes oportunidades e desafios aos hábitos sociais e aos limites entre espaços públicos e privados e culturas digitais. Consequentemente, existe um potencial muito grande a ser aproveitado para a educação e cidadania. $\mathrm{O}$ que está refletido nas opiniões da Universität Siegen et al. (2010), que considera que mudanças baseadas nas TIC podem realmente ter efeitos substanciais e duradouros na sociedade.

Piconez (2008) argumenta a favor das tecnologias digitais e seu uso educacional como um novo paradigma. Se há um novo mundo, há a necessidade de uma nova educação. E esta têm colocado mudanças no processo de aprender. Aponta que a possibilidade do uso da mobilidade na aprendizagem consegue envolver "alunos de diferentes locais e experiências atendendo seus estilos de aprendizagem", integrando os participantes, construindo coletivamente o aprendizado e incorporando novos conceitos de ensino e de aprendizagem em um mundo repleto de informação e de constante transição.

Para Calvo, Arbiol \& Iglesias, (2014), "a Comunicação digital entre grupos de alunos e entre alunos e professores tornou-se popular durante a última década através de vários canais: E-mail, SMS, grupos 
no Facebook, Twitter, e recentemente WhatsApp". Como cada uma dessas ferramentas tem características, potenciais e restrições diferentes que influenciam a sua adequação para fins de aprendizagem, elas devem ser planejadas a fim de usa-las no processo educacional".

Batista (2012) apud Prensky (2010), cita que "os jovens da sociedade contemporânea estão conectados ao mundo e aos colegas de uma forma totalmente diferente das gerações anteriores e, como estudantes, suas necessidades não são as mesmas de épocas passadas". Da mesma forma que Veen e Vrakking (2009) argumentam que é muito grande o número de pessoas que já nasceram em contato com a cultura cibernética, formando uma geração aprende desde muito cedo que as tecnologias digitais permitem acessar, de forma rápida, diversas informações e facilitam muito a comunicação. Esta geração de jovens, diferente de seus ancestrais, conseguem direcionar a atenção, simultaneamente, a múltiplas mídias e isso contrasta com a postura tradicional de contemplação sobre um determinado conteúdo, adotada, em geral, nas escolas. Ora, se o aluno mudou torna-se necessária a mudança dos métodos de ensino e "apesar de saber que as novas tecnologias de informação nos cercam, elas ainda não são amplamente utilizadas pelos professores. Estes autores pontuam que nos próximos anos essas ferramentas serão essenciais nas salas de aula. Apesar de já fazerem parte dos materiais os quais os alunos levam para as salas de aula, o celular ainda é pouco utilizado como recurso didáticopedagógico".

Keegan (2007), Sharples (2009), Traxler (2009), Schofield (2011), concordam que "as tecnologias móveis sem fio podem contribuir para a aprendizagem" E referem-se a este campo de pesquisa como mobile learning (m-learning), uma "área, ainda emergente e em rápida expansão, de pesquisa e prática educacional em instituições de ensino e em locais de trabalho e, também, no âmbito na educação informal e que tem motivado pesquisas".

Dudeney e Hocky (2007) pontuam que "nos próximos anos a tecnologia móvel será essencial nas salas de aula. E que apesar de já fazerem parte dos materiais que os alunos levam para as salas de aula, o celular ainda é pouco utilizado como recurso didáticopedagógico".

O termo $m$-learning evoca diversas interpretações, dado a multiplicidade de usos potenciais, e sobretudo a incipiência do uso educacional. Para Sharples (2009), é uma área que estuda como a mobilidade dos alunos, favorecida pela tecnologia pessoal e pública, pode contribuir para o processo", o que coloca o foco no usuário, da mesma forma que Pelissoli e Loyolla (2004), que considera o m-learning "a união de várias tecnologias de comunicação e processamento de dados que possibilitam a alunos e educadores uma interação mais eficaz, através de dispositivos móveis como notebooks, celulares, smartphones, etc". Já Sariola. (2001), aponta que a expressão "mobile learning" parece ter forte apelo comercial, colocando o foco nas marcas envolvidas, e Georgiev (2004) volta o foco para a tecnologia, quando aponta que "é uma forma de e-learning, desenvolvida por meio de aparelhos computacionais móveis", e que serviria a "atender alguns aspectos que ainda prejudicam a e-learning, como falta de infraestrutura de acesso à Internet nos países em desenvolvimento e a questão da mobilidade dos alunos".

Um conceito rico e abrangente para o m-learning é o dado por Traxler (2009), por Sharples (2009) e por Caudill (2007), é o que o considera "não é apenas uma simples variação de educação a distância que ocorre por meio de dispositivos móveis, ou somente uma extensão da aprendizagem em sala de aula para ambientes menos formais. É um modo ainda mais flexível de educação, capaz de realmente criar novos contextos de aprendizagem através da interação entre pessoas, tecnologias e ambientes".

Outros autores também tentam conceituar o m-learning, dentro do aspecto educacional. Santos Costa (2013), apud Geddes (2004), conceitua de forma bem generalizada como a "aquisição de qualquer conhecimento e habilidade através da utilização de tecnologia móvel, em qualquer lugar, a qualquer hora, resultando em uma alteração do comportamento do aprendiz que pode indicar o resultado de aprendizagens" e cita Sharma e Kitchens (2006), que referem-se ao m-learning não como uma ferramenta, mas como um processo de "aprendizagem que enfatiza as vantagens dos dispositivos móveis, das tecnologias de comunicação ubíquas e das interfaces inteligentes", valorando mais o processo do que a tecnologia.

Eisenberg (2007), acredita que o m-learning "um esforço bem intencionado para ajudar ainda mais a humanidade a potencializar sua aprendizagem, em um mundo conectado", refletindo o seu uso a generalização do uso dos equipamentos móveis, e que isto permite aos aprendentes "a qualquer hora e em qualquer lugar um grande acesso à informação que está organizada e acessível predominantemente fora do domínio da escola", reforçando o argumento da ruptura com o paradigma de exclusividade geo-temporal do modelo de ensino tradicional, reforçando as opiniões de Mifsud (2002) e Tamminem (2004), que defendem que "as aplicações de tecnologias para m-learning demandam quebra de paradigmas, pois o aprendizado não mais ocorre em locais formais e fixos'.

Santos Costa, (2013, apud Brown, 2010), traz à tona a interatividade, autonomia e individualização do aprendizado permitidas pelas tecnologias ubíquas atuais, pois estas sendo instantaneamente utilizáveis, permitem aos usuários personalizar o conteúdo, inserir dados e também gerar conteúdo. Estes argumentos complementam a opinião de Sharples (2009), que "a 
mobilidade não deve ser apenas entendida em termos do movimento espacial, mas também em termos de transformações temporais e diminuição de fronteiras, aumentando os horizontes da aprendizagem e do acesso à informação".

Para Sharples (2009), existem dois componentes no conceito de m-learning. O primeiro é a definição de mobile (mobilidade) e o segundo é o de learning (aprendizagem). Embora o termo learning não deixe dúvidas, o conceito mobile, pode reportar-se tanto às tecnologias móveis, como à mobilidade do estudante $\mathrm{e}$ também à mobilidade dos conteúdos e contextos. Neste sentido, "a mobilidade não deve ser apenas entendida em termos do movimento espacial, mas também em termos de transformações temporais e diminuição de fronteiras, aumentando os horizontes da aprendizagem e do acesso à informação".

$\mathrm{Na}$ busca de conceituação mais abrangente, e consolidação dos múltiplos aspectos envolvidos, Silva (2013) leva em conta a nova configuração das interações nesse processo, onde os atores se encontram separados fisicamente e, muitas vezes, geograficamente e atinar para com a possibilidade de aquele ocorrer distante dos espaços físicos formais de educação. Silva (2013), considera que o m-learning cumpre um papel importante no desenvolvimento dos métodos educativos, e tratase de uma nova forma de relação entre indivíduos aprendizes e aprendizado. Considera o m-learning, vantajoso frente ao e-learning, (tratando-o como modelos diferentes de tecnologia), pois inova mostrando que a tecnologia móvel, que mediará o conhecimento e os indivíduos aprendizes, permite que as ações no ato educativo sejam negociadas, dinamizadas, para além de contextos pré-estabelecidos.

Tarouco (2014), Traxter (2005) e Valentin (2009) consideram que as características de disponibilidade, acessibilidade e capilaridade da tecnologia móvel permite a aprendizagem móvel, já que indivíduos que aprendem podem estar fisicamente e geograficamente distantes uns dos outros e ou em espaços físicos formais de aprendizagem".

O atual estágio da sociedade e o grau de uso se tecnologias, apontam que "as aplicações de TICs para m-learning demandam uma quebra de paradigmas, uma vez que o aprendizado não mais ocorre em locais formais e fixos". (Mitsud (2002) e Tamminem (2004))

Oliveira (2014) considera a tecnologia do m-learning em "forte expansão como apoio ao ensino presencial e não como meio único para a condução de um curso", apontando a possibilidade do uso misto, e julga necessário do planejamento e organização, pois o "dinamismo da ferramenta pode interferir negativamente nos resultados esperados", como citado por Klein (2007).

Oliveira (2014) argumenta que a tecnologia móvel se encontra bastante disseminada na sociedade, e que isto pode o processo de aprendizagem mais interativo e amigável, sendo o aplicativo WhatsApp uma alternativa eficaz para o ensino-aprendizagem, aumentando as relações pessoais entre os membros do grupo e a sensação de comunidade e colaboração do grupo.

O m-learning para Sharples (2009,) reflete a era atual é a mobilidade pessoal e tecnológica e, com estes novos modelos sociais deve-se conceber a aprendizagem de forma diferente, unindo os reais e virtuais, criando comunidades de aprendizagem entre pessoas em movimento, provendo informações sob demanda e apoiando uma vida inteira de aprendizagem.

As TICs (Tecnologias de Informação e Comunicação) hoje adotadas para automação de atividades de trabalhadores móveis podem ser utilizadas também para aprendizagem em trabalho. Os "tempos mortos" podem ser espaços para acessar ou rever materiais didáticos" (KOSCHEMBAHR,2005).

Klein e Reinhard (2006), embora considerem que "as tecnologias móveis podem potencializar a aprendizagem por toda a vida - individualizada, centrada no aprendiz, interativa, situada, colaborativa e ubíqua", apontam também para o caráter dúbio tecnologia, uma vez que traz decorrências negativas, "como: a sobrecarga de informações; o aumento da complexidade nas interações em diferentes locais e momentos (de forma síncrona e assíncrona), a quebra de fronteiras entre vida pessoal e de trabalho com prejuízos à qualidade de vida

Melo (2014) aponta o aspecto tecnológico e democrático da plataforma m-learning, demonstrando seu baixo custo e, portanto, a sua possibilidade massiva de uso em sociedades de baixo desenvolvimento social e econômico, ampliando a possibilidade transformadora da educação.

Klein (2007) aponta, por ocasião do estudo exploratório sobre a difusão das práticas de m-learning no contexto brasileiro, especialmente no que diz respeito à sua aplicação em nível organizacional, demonstrou que ainda eram raros os casos de aplicação do m-learning no contexto organizacional no Brasil, e que a maior parte das referências e casos de desenvolvimento de soluções ou de práticas de m-learning se encontram no meio acadêmico, especialmente no ensino superior, com o uso de poucas funcionalidades e recursos, e nenhuma prática rotineira (m-learning efetivamente incorporado nos processos de ensino-aprendizagem). Isso indicava, a época o estágio emergente de desenvolvimento do m-learning também no meio acadêmico brasileiro. E além desta pouca utilização, apontou que os projetos e aplicações encontrados no meio acadêmico, apresentavam modelos, frameworks ou protótipos de software ainda não aplicados no meio acadêmico brasileiro e que a maioria das referências e projetos localizados no meio acadêmico possuía 
enfoque tecnológico sendo poucas as que se preocupam com aspectos econômicos ou de gestão, com questões pedagógicas ou com elementos contextuais e sociais relacionados à adoção das tecnologias e práticas de m-learning.

Batista (2012), aponta que o m-learning é ainda um campo recente de pesquisa e, portanto, desafiador. Mas considera que o comportamento da sociedade atual, em relação aos avanços tecnológicos, aponta para o uso de dispositivos móveis na educação, como uma alternativa que não deve ser ignorada. Reconhece que as características da plataforma (interatividade, mobilidade, trabalho em equipe, aprendizagens em contextos reais), devem ser usados na mobilização do processo de aprendizagem, além de permitir o uso instantâneo de mídias audiovisuais. Da mesma forma, Klein (2007) coloca ele como alternativa ao modelo tradicional de EAD.

Para Traxler (2009), "a própria conceituação de m-learning é ainda emergente e pouco clara". Algumas definições, para o autor se restringem ao aspecto tecnológico, privilegiando o recurso, em detrimento dos aspectos didáticos e pedagógicos. Neste aspecto Sharples et al. (2009), defende que "o foco sobre a tecnologia não ajuda a compreensão da natureza de m-learning, pois ignora o contexto mais amplo da aprendizagem como parte de um estilo de vida cada vez mais móvel". Para Batista (2012 apud Pachler 2010), servir muito mais do que simplesmente viabilizar formas de fornecimento de materiais pedagógicos em dispositivos móveis, e que tempo, espaço, ambientes de aprendizagem, conteúdo, tecnologia, aspectos mentais e aspectos metodológicos, estão relacionados e não podem ser isolados e pois influenciam uns aos outros" (Laouris e Eteokleous, 2005).

Schofield (2011) analisa os motivos que destacam m-learning como uma possibilidade educacional, e aponta alguns aspectos inter-relacionados:

a) Avanços tecnológicos e altos níveis de penetração dos celulares, que fizeram desses dispositivos alvos ideais para o desenvolvimento de aplicativos educacionais;

b) Características e comportamentos dos jovens da geração digital, que impulsionam mudanças nas propostas de ensino para todas as gerações;

c) Normas sociais que também estão evoluindo rapidamente;

d) Vantagens próprias do uso de dispositivos móveis na educação, como, por exemplo, a possibilidade de eliminação de certas barreiras tecnológicas em decorrência do uso de recursos do próprio aluno.

Estas inter-relações apontadas por Schofield, concordam com Traxler (2009), que considera que as " (inter) relações entre educação, sociedade e tecnologia estão cada vez mais dinâmicas". E embora o m-learning, ainda um campo imaturo, tanto em termos tecnológicos quanto pedagógicos, "pode trazer contribuições à educação, à medida que avançam as pesquisas na área".

Marçal (2005), trata dos objetivos de uma aplicação m-learning são:

a) Melhorar os recursos para o aprendizado do aluno, que poderá contar com um dispositivo computacional para execução de tarefas, anotação de ideias, consulta de informações via Internet, registro de fatos através de câmera digital, gravação de sons e outras funcionalidades existentes;

b) Prover acesso aos conteúdos didáticos em qualquer lugar e a qualquer momento, de acordo com a conectividade do dispositivo;

c) Aumentar as possibilidades de acesso ao conteúdo, incrementando e incentivando a utilização dos serviços providos pela instituição, educacional ou empresariais.

d) Expandir o corpo de professores e as estratégias de aprendizado disponíveis, através de novas tecnologias que dão suporte tanto à aprendizagem formal como à informal.

e) Fornecer meios para o desenvolvimento de métodos inovadores de ensino e de treinamento, utilizando os novos recursos de computação e de mobilidade".

E embora vários autores apontam como vantajoso o uso do m-learnig, Klein (2007), considera aspectos negativos ser de correntes de tecnologias móveis, "tais como o excesso de informações, sem que o receptor consiga processá-las para uma utilização eficiente; as interações adquirirem um nível bastante alto de complexidade, além do impacto na qualidade de vida das pessoas, já que esta tecnologia possibilita a quebra da fronteira entre a vida pessoal e a vida profissional, fazendo com que estas se interliguem cada vez mais, além da qualidade desse aprendizado, se o m-learning não fica restrito a um nível informacional".

Batista (2009), embora reconheça a interatividade, mobilidade, alcance de maior número de pessoas, prática de trabalho em equipes, aprendizagens em contextos reais, entre outros são vantagens próprias da tecnologia do e-learning, também aponta limitações e vantagens da utilização de dispositivos móveis em educação: tamanho de tela e de teclas e adaptação de aplicações desenvolvidas para Web. Limitações são acrescidas por Costa (2006): "pouco espaço de armazenamento; baixo poder de processamento; bateria com pouca autonomia; dificuldades de acesso à Internet Móvel, etc".

A análise sistemática de publicações científicas sobre o tema, Mülbert (2011) aponta o m-learning como "campo de pesquisa emergente, reconhecendo o contexto de crescente mobilidade dos sujeitos, facilitado pela disponibilidade cada vez maior das tecnologias móveis, encontrando-se aí campo fértil para sua expansão".

Mülbert (2011), reforça a necessidade de que 
não se mantenha o foco exclusivamente no aspecto tecnológico, privilegiando os aspectos pedagógicos e didáticos.

Belém (2014) considera que no uso da plataforma de m-learning, evoca que o foco na participação e primordial no engajamento dos alunos, e que mais importante que a tecnologia, são as interações pelo poder que tem de promover condições para a motivação na aprendizagem. Defende que o uso de tecnologias móveis promove a compreensão que a aprendizagem pode ocorrer de maneira simples e acessível, utilizando os recursos que se dispõem na atualidade, garantindo a prática na comunicação com seu interlocutor fora do ambiente formal de ensino, rompendo, portando com os paradigmas geográficos e temporais dos processos atuais da educação.

Bouhnik, D., \& Deshen, M. (2014), em pesquisa exploratória com método qualitativo, tendo sido realizada entrevistas com os professores que utilizam o aplicativo wattsapp para se comunicar com os seus alunos, demonstrou que este é utilizado em quatro finalidades: comunicação com os alunos; desenvolvimento da interação social; propiciar o estabelecimento de diálogos e compartilhamento de conhecimentos e como uma plataforma de aprendizagem. 1 evidencia as vantagens do uso (a facilidade do uso, o baixo custo, a disponibilidade e imediatismo) e aponta desafios ao seu uso (nem todos os estudantes do ensino médio possuem um smartphone e a possibilidade do desvio de foco.

Em trabalho recente, Reis (2014), se propôs a mostrar que o aplicativo de celular WhatsApp pode ser utilizado como auxilio a atividade docente, permitindo a troca de informações entre alunos/alunos e alunos/ professor, e considera que como os jovens são adeptos ao aplicativo, pois faz parte de sua rotina social, pode ser utilizado com ganho na aprendizagem. Reforça, portanto a afirmação de Souza (2014), que aponta que "cerca de $95 \%$ dos jovens e adultos brasileiros com idades entre 15 e 33 anos se consideram viciados em tecnologia e $63 \%$ utilizam o aplicativo WhatsApp". Estas considerações reforçam os argumentos de Pretto (2010), quando o mesmo defende que "a atividade educativa assume proporções significativas cada vez mais generalizada presença das tecnologias digitais de informação e comunicação (TIC) em toda a sociedade, pois as redes sociais levam as pessoas a estarem conectadas com assuntos diversos, com pessoas diferentes, trocando conhecimentos, uma rede interligada em todos os sentidos".

Com o mesmo entendimento, a pesquisa realizada por Santos Costa (2013), em que buscou explorar as potencialidades com o uso do celular no ensino aprendizagem de língua inglesa como língua estrangeira com alunos da escola pública, considerou que o usodo celular foi facilitador para estimular a transformação da integração das cinco habilidades linguísticas no ensino de inglês, elevando o nível de desempenho linguístico dos alunos e permitindo que a aprendizagem acontecesse em novas formas, apontando que o Mobile learning ajudou a melhorar a aprendizagem de línguas, colocando os alunos em um "contexto real e tornando o processo mais atraente, motivador e interessante, sendo o uso dos dispositivos móveis mais uma possibilidade de ferramenta de aprendizagem ao longo da vida para qualquer um, em qualquer lugar e em qualquer momento", apontando também para o rompimento do paradigma geo-temporal da escola atual.

Gomes (2011), reconhece que podem surgir cursos novos antes impensáveis sem a tecnologia móvel e seus recursos. Mas alerta que que existe necessidade com o seu uso, pois "para cada situação de curso, ou proposta pedagógica, diferentes soluções e abordagens podem ser utilizadas", e defende que nem todo tipo de curso poderá ser beneficiado com o m-learning.

Com julgamento também criterioso do uso da tecnologia móvel, Brantes (2012), "considera que o uso do m-learning depende de como os alunos avaliam as suas tarefas de aprendizagem em relação aos benefícios que irão obter no curto e no longo prazo". Este raciocínio tira de foco os aplicativos usados, trazendo-o para o aprendente, e em especial a sua capacidade de se auto avaliar seu aprendizado, reforçando a parcimônia de uso apontada por Gomes (2011).

Oliveira (2014), descreve uma experiência com m-learning, para professores e tutores da UFPB Virtual onde foi utilizado o aplicativo para dispositivos móveis Wattsapp, e neste conclui que seu uso traz uma inovação no processo de ensino-aprendizagem, "com uma forte tendência a sua expansão como apoio ao ensino presencial". E da mesma forma que citam Brantes (2012) e Gomes (2011), aponta a necessidade de planejamento e organização, para o seu uso. Aponta também que na experiência realizada verificou que existe uma ampliação da motivação e satisfação dos cursistas, com o aumento das relações pessoais e o desenvolvimento da sensação de pertencimento e colaboração do grupo. Como fator negativo, observado na experiência ocorre a possibilidade de dispersão do foco pelo dinamismo inerente ao aplicativo, conforme apontado no trabalho de Bouhnik, D., \& Deshen, M. (2014).

Em relação ao aumento da motivação e ampliação das relações entre os alunos, Araújo (2015), aponta o mesmo fenômeno pois percebe que, na experiência que realizou com alunos de Filosofia, ocorreu um aumento do nível de interação entre os estudantes aumentou rapidamente e que ocorre simultaneamente distanciamento do assunto proposto.

Souza (2015) também em uma experiência com o uso de m-learning, para alunos, faz uma avaliação da opinião de estudantes sobre a inclusão de redes sociais - Facebook, WhatsApp e Instagram- como plataformas facilitadoras da aprendizagem, e esta traz a perspectiva 
dos alunos confirmando que podem ser usadas de forma vantajosa no ensino, pois conforme Pechi (2011), "cada vez mais cedo, as redes sociais virtuais passam a fazer parte do cotidiano dos alunos", e que despertam interesse nos usuários aprendentes, pois permitem a criação e troca de conteúdo, transformando o processo de aprendizagem interativo e compartilhado (Kalpan,2011).

Uma outra experiência de avaliação de m-learning foi levada a termo por Sousa (2014), em que avalia se as redes sociais são utilizadas como prática pedagógica e a sua a possível eficácia do uso deste instrumento para um estudo mais dinâmico e interativo entre professoraluno. Os resultados do autor demonstraram de forma considerável que as "redes sociais são bem utilizadas pelos alunos, o que não ocorre pelos professores", concordando com Veen e Vrakking (2009). Aponta que na visão dos alunos o uso pode atrapalhar de forma que distrai a atenção do aluno (Bouhnik, D., \& Deshen, M. (2014). Considera que, "apesar das redes sociais não ter sido criadas para atender finalidades educacionais elas estão presentes no cotidiano e devem ser estimulados o seu uso como uma forma a ajudar na aprendizagem e na relação entre professor e aluno, atendendo as finalidades sociais e trazendo novas técnicas para tornar mais interessante o meio ao estudo".

Schlemmer (2007), realiza um estudo exploratório sobre as práticas de m-learning no contexto brasileiro, em especial no mundo corporativo e acadêmico. Relata que seu estudo demonstrou que a preocupação predominante com relação ao m-learning, tanto no contexto da educação corporativa quanto no contexto acadêmico, está fortemente relacionada às questões tecnológicas, em detrimento as questões epistemológicas e didático-pedagógicas, conforme apontado nas próprias definições conceituais de m-learning. Como trata-se de um trabalho mais antigo, pode representar o ingresso na tecnologia, ainda descolada do processo pedagógico.

\section{Resultados e Discussões}

A amostra constou de 66 (sessenta e seis) professores pertencentes as redes sociais do pesquisador e que participaram no período de 27 de maio de 2015 a 16 de julho de 2015. Foram colhidas as respostas através de formulário eletrônico do Google, e que mencionava os objetivos e os limites da pesquisa. Foi também disponibilizado no formulário eletrônico o termo de consentimento livre e esclarecido, orientando a condição de sigilo e voluntariedade da pesquisa.

A pesquisa teve características de survey. "Surveys são frequentemente realizados para permitir enunciados descritivos sobre alguma população, isto é, descobrir a distribuição de certos traços e atributos". Nestes, o pesquisador não se preocupa com o porquê de a distribuição observada existir, mas com o que ela é (Babbie, 2005: 96). Com este entendimento, trata-se de um método adequado a pesquisa realizada, de caráter prospectivo e inicial.

A análise da amostra (Tabela 1) demonstra que a concentração maior dos respondentes é de professores que atuam no Ensino Superior, Ensino Médio e Educação Fundamental. Sendo que na amostra 48 professores (73\%) estão envolvidos em atividade educacional de estudantes além da educação fundamental, público que possivelmente teria mais dificuldade de usar m-learning.

Esta percepção é coerente com o que aponta

Tabela 1. Nível educacional você exerce as atividades de docência

\begin{tabular}{cc}
\hline Nível educacional & Total \\
\hline Educação Infantil & 01 \\
Educação Fundamental & 17 \\
Ensino Médio & 17 \\
Ensino Superior & 24 \\
Pós-graduação & 07 \\
\hline
\end{tabular}

Fonte. do autor

diversos autores, quando citam a dispersão que o aplicativo pode determinar, e que certamente seria mais exponencial em educandos mais jovens, presentes no ensino fundamental.

Os professores pesquisados em sua maioria declaram que exercem seus mais de 05 anos, podendo, portanto, considera-los como experientes na docência e com opiniões relevantes ao estudo (Tabela 2).

A Tabela 3, evidencia que dos pesquisados,

Tabela 2. Tempo que desenvolve atividades na docência

\begin{tabular}{cc}
\hline Tempo de docência & Total \\
\hline De 01 ano a 05 anos & 12 \\
De 06 anos a 10 anos & 18 \\
De 11 anos a 15 anos & 11 \\
De 16 anos a 20 anos & 03 \\
De 20 anos a 25 anos & 09 \\
Mais de 25 anos & 13 \\
\hline
\end{tabular}

Fonte. do autor

a maioria tem formação em Ciências Sociais, representando $56 \%$ da amostra, seguido por Ciências Exatas e Tecnológicas (23\%) e Ciências biológicas e da Saúde (17\%)

Dos professores que responderam a pesquisa $41 \%$ eram de instituições privadas, $35 \%$ de escolas estaduais e $18 \%$ de escolas municipais. No computo geral há uma maioria de escolas públicas (55\%) (Tabela 4).

Com esta análise anterior conforma-se o perfil do pesquisado: Professores de escola pública de nível 
superior e médio, com exercício profissional na docência de seis a dez anos, com formação em Ciências Humanas e Sociais.

$\mathrm{Na}$ Tabela 5, a maioria absoluta (95\%) declara

Tabela 3. Área de formação dos pesquisados

\begin{tabular}{cc}
\hline Área de formação & Total \\
\hline Ciências Humanas e Sociais & 37 \\
Ciências Exatas e Tecnológicas & 15 \\
Ciências Biológicas e da Saúde & 11 \\
Curso Normal & 02 \\
Ciências Agrárias & 01 \\
\hline
\end{tabular}

Fonte. do autor

Tabela 4. Tipo de vínculo profissional na docência

\begin{tabular}{cc}
\hline Tipo de vínculo & Total \\
\hline Privado & 27 \\
\hline Público Estadual & 23 \\
\hline Público Municipal & 12 \\
\hline Religioso & 03 \\
\hline Público Federal & 01 \\
\hline
\end{tabular}

Fonte. do autor

usar o WhatsApp, sendo que o uso em Comunicação Pessoal é de $65 \%$, seguido de Uso no trabalho (14\%), Uso educacional (11\%) e Uso em lazer (10\%)

Este aspecto está diretamente ligado ao

Tabela 5. Tipo de uso do WhatsApp

\begin{tabular}{cc}
\hline Tipo de uso & Total \\
\hline Comunicação pessoal & 41 \\
Trabalho & 09 \\
Educacional & 07 \\
Lazer & 06 \\
\hline
\end{tabular}

Fonte. do autor

objetivo primeiro do desenvolvimento do aplicativo: a comunicação. Entretanto sua mobilidade, baixo custo e adesão dos usuários o trouxe para usos antes inexplorados.

$\mathrm{Na}$ amostra (Tabela 6), os professores quando perguntados especificamente para o uso educacional, a que atividade o WhatsApp é mais útil, os professores apontam, como foi possível respostas combinadas, obteve-se um total de 80 respostas, que apontam os seguintes usos: Relação interpessoal com alunos (40\%), Consulta para dúvidas dos alunos (31\%), Uso de mídia educacional (18\%) e Distribuição de conteúdo (11\%). Fica evidente que se sobrepõe a possibilidade de relação ao uso estrito como ferramenta de conteúdo.
Tabela 6. Uso educacional do WhatsApp

\begin{tabular}{cc}
\hline Atividade em que usa & Total \\
\hline Relação interpessoal com alunos & 32 \\
Consulta para dúvidas dos alunos & 25 \\
Uso de mídia educacional & 14 \\
Distribuição de conteúdos & 9 \\
\hline
\end{tabular}

Fonte. do autor

Embora outros usos sejam citados, fica bastante claro a possibilidade da ampliação da relação interpessoal com alunos, se sobrepondo a usos que poderiam ser mais clássicos em educação: o uso de mídias e a distribuição de conteúdo. Estes usos estão alinhados com a opinião de Silva (2013), que considera que o m-learning cumpreum papel importante no desenvolvimento dos métodos educativos, e trata-se de uma nova forma de relação entre indivíduos aprendizes e aprendizado, o que se vê na pesquisa, que evidencia uma intenção de ampliar a inter-relação entre professores e alunos.

Entretanto, quando a questão colocada sobre o uso potencial do WhatsApp (Tabela 7), em modelo Likerty, evidencia que o aplicativo está fortemente voltado a distribuição de conteúdo $(92,42 \%)$, seguido pela possibilidade de interação entre alunos $(86,36 \%)$, como ferramenta para tirar dúvidas $(71,21 \%)$.

É menor a expressão de seu uso como mobilizador de interação entre alunos e professores $(66,67 \%)$. Parece haver uma divergência entre o que é visto como possibilidade e a forma que tem sido utilizada, possivelmente por ser ainda incipiente o uso do aplicativo como ferramenta educacional.

Na Tabela 8, estão relacionadas as dificuldades apontadas para o uso do WhatsApp como ferramenta educacional. Os professores pesquisados apontam, também em uma questão de modelo Likerty, que não parece ser uma dificuldade o custo dos equipamentos $(34,85 \%)$. Os problemas na interpretação dos professores, para o uso do aplicativo está na questão técnica do fornecimento de banda larga $(68,18 \%)$, mais até que a possibilidade de dispersão e perda de foco por parte do aluno $(66,67 \%)$ e o alheamento às relações pessoais $(59,09 \%)$

Os resultados a respeito das dificuldades com a banda larga reforçam esta limitação apontada por Batista (2009), e confrontam-se com Pellanda (2009), que cita como "expressivo o aumento de conexões resultantes da tecnologia móvel e que esta tem proporcionado diferentes oportunidades e desafios aos hábitos sociais e aos limites entre espaços públicos e privados e culturas digitais". Como vivemos em um país de dimensões continentais e com dispersão heterogênea de tecnologias, este aspecto necessitaria de ser avaliado com um recorte geográfico, pois a divergência pode estar surgindo por avaliações de áreas geográficas diferentes. 
Tabela 7. Usos potenciais do Whatsapp na educação

\begin{tabular}{|c|c|c|c|c|c|}
\hline Uso potencial & $\begin{array}{c}\text { Concordo } \\
\text { completamente }\end{array}$ & Concordo & Indiferente & Discordo & $\begin{array}{c}\text { Discordo } \\
\text { completamente }\end{array}$ \\
\hline \multirow{2}{*}{$\begin{array}{l}\text { Como distribuidor } \\
\text { de conteúdos }\end{array}$} & $40,91 \%$ & $51,52 \%$ & $3,03 \%$ & $4,55 \%$ & $0,00 \%$ \\
\hline & \multicolumn{2}{|c|}{$92,42 \%$} & & \multicolumn{2}{|r|}{$4,55 \%$} \\
\hline \multirow{2}{*}{$\begin{array}{l}\text { Como mobilizador } \\
\text { da interação entre } \\
\text { os alunos }\end{array}$} & $39,39 \%$ & $46,97 \%$ & $6,06 \%$ & $7,58 \%$ & $0,00 \%$ \\
\hline & \multicolumn{2}{|c|}{$86,36 \%$} & & \multicolumn{2}{|c|}{$7,58 \%$} \\
\hline \multirow{2}{*}{$\begin{array}{c}\text { Como mobilizador } \\
\text { da interação } \\
\text { entre alunos e } \\
\text { professores }\end{array}$} & $24,24 \%$ & $42,42 \%$ & $12,12 \%$ & $19,70 \%$ & $1,52 \%$ \\
\hline & \multicolumn{2}{|c|}{$66,67 \%$} & & \multicolumn{2}{|c|}{$21,21 \%$} \\
\hline Como ferramenta & $22,73 \%$ & $48,48 \%$ & $10,61 \%$ & $13,64 \%$ & $4,55 \%$ \\
\hline $\begin{array}{c}\text { para "tirar } \\
\text { dúvidas" com o } \\
\text { professor }\end{array}$ & \multicolumn{2}{|c|}{$71,21 \%$} & & \multicolumn{2}{|c|}{$18,18 \%$} \\
\hline
\end{tabular}

Fonte. do autor

Tabela 8. Principais dificuldades apontadas para o uso do WhatsApp

\begin{tabular}{cccccc}
\hline $\begin{array}{c}\text { Dificuldades do } \\
\text { uso }\end{array}$ & $\begin{array}{c}\text { Concordo } \\
\text { completamente }\end{array}$ & Concordo & Indiferente & Discordo & $\begin{array}{c}\text { Discordo } \\
\text { completamente }\end{array}$ \\
\hline $\begin{array}{c}\text { Alto custo dos } \\
\text { equipamentos }\end{array}$ & $7,58 \%$ & $27,27 \%$ & $25,76 \%$ & $34,85 \%$ & $4,55 \%$ \\
$\begin{array}{c}\text { Dificuldades de } \\
\text { banda larga pelos } \\
\text { alunos }\end{array}$ & $27,27 \%$ & $40,91 \%$ & $12,12 \%$ & $16,67 \%$ & $3,03 \%$ \\
$\begin{array}{c}\text { Possibilidade de } \\
\text { dispersão perda de } \\
\text { foco }\end{array}$ & $19,70 \%$ \% & $46,97 \%$ & $15,15 \%$ & $18,18 \%$ & $0,00 \%$ \\
$\begin{array}{c}\text { Redução das } \\
\text { interações pessoais } \\
\text { privilegiando as } \\
\text { virtuais }\end{array}$ & $66,67 \%$ & & & $19,70 \%$ \\
\hline
\end{tabular}

Fonte. do autor

As opiniões dos professores a respeito da possibilidade de perda de foco e dispersão, também foi apontada Bouhnik, D., \& Deshen, M. (2014), sendo considerado um fator desfavorável ao uso.

$\mathrm{Na}$ questão sobre o conhecimento sobre o uso de aplicativos de m-learning ou do WhatsApp como ferramenta educacional, 31 professores (45\%) declararam não conhecer e 35 ter conhecimento (55\%). Estes resultados confirmam opiniões de autores que apontam as ferramentas de m-learning como um novo entrante nos processos educacionais.

\section{Conclusões e considerações finais}

Nunca, em tempo algum, a sociedade experimentou tanto dinamismo nas comunicações interpessoais, em especial pela mediação que as tecnologias de comunicação têm permitido. Além de permitir o número expressivo de interações, os atuais estados das mídias de comunicação permitem a transferência de grandes volumes de dados, que se concretizam em forma de textos, livros, imagens, áudios e vídeos.

$\mathrm{O}$ advento da tecnologia de celulares e mais recentemente dos smartphones, tem impactado a forma das pessoas interagirem, se relacionarem e se informarem. É um fenômeno nunca antes visto, pois a variedade de marcas e modelos e preços variados, permite o acesso aos mais diversos grupos de usuários. Por onde se olha hoje, identifica-se a capilaridade e disseminação destes equipamentos e com as características identificadas nestes aparelhos móveis, é natural que sejam identificadas as potencialidades para a educação.

De fato, muitas referências são encontradas na bibliografia, mas que apontam para um uso ainda 
incipiente e pouco estruturado. Das experiências relatadas nota-se que o uso educacional mais explorado é o para qual o aplicativo foi pensado: a interação entre pessoas.

A pesquisa de campo realizada, também apontou para isto. Embora os professores demonstrem a possibilidade de uso, este está marcadamente na potencialidade da interação entre os atores da educação. Também fica claro que alguns elementos desabonam o uso, como a perda de foco e a distração no uso.

$\mathrm{O}$ uso do m-learning ainda está em fase embrionária no contexto brasileiro, mas a sua disseminação sociedade atual, e a passibilidade do desenvolvimento da tecnologia de banda larga móvel, que permitirá o acesso cada vez maior da população, a baixo custo, com maior velocidade e volume de transmissão de dados, sugerem que o uso de dispositivos móveis na educação é algo que não deve ser ignorado ou pensado como improvável em pouco tempo.

A reflexão que se faz é que para além do uso do aplicativo como ferramenta educacional, o que se observa é que, a exemplo do que ocorre na sociedade em geral, alunos e professores buscam a interação pessoal, entre si, permitida por esta tecnologia, muito além de ser um distribuidor de conteúdo. Isto aponta que, mais que o aspecto tecnológico envolvido na educação mediada por plataformas móveis, a educação da sociedade contemporânea parece romper de vez com os antigos modelos conteúdistas, adotando cada vez mais as relações interpessoais como o modelo necessário, o que se refletem na interatividade, $\mathrm{o}$ trabalho em equipe, a na aprendizagem em contextos reais, que permitem o m-learning.

Por se tratar de tecnologia relativamente jovem e considerando a pouca disseminação como ferramenta educacional, existe a possibilidade de ampliar o estudo, buscando expandir suas potencialidades em especial na demanda soluções tanto pedagógicas quanto tecnológicas a fim de enfrentar os desafios apontados pelos professores pesquisados.

\section{Referências}

ARAUJO Câmara; BOTTENTUIT JUNIOR, João Batista. O Aplicativo de Comunicação WhatsApp como Estratégia no Ensino de Filosofia. Temática (João Pessoa. Online), v. XI, p. 11-23, 2015.

BABBIE, E. (2005). Métodos de Pesquisas em Survey. Belo Horizonte, MG: Editora UFMG.

BATISTA, S. C. F. . Mobile Learning: Reflexões sobre o Tema. In: VII Congresso Integrado de Tecnologia da Informação, 2012, Campos dos Goytacazes. Anais do VII Congresso Integrado de Tecnologia da Informação, 2012

BATISTA, S. C. F. ; BEHAR, P. . M-learning e Matemática: Mapeando Recursos e Modalidades Educacionais. RENOTE. Revista Novas Tecnologias na Educação, v. 7, n.3, p. 307-316, 2009

BELÉM, B. C. . Short Message Service e Whatsapp: Interações por Meio de Dispositivos Móveis. In: Congresso Nacional Universidade, EAD e Software
Livre, 2014, Belo Horizonte. Anais do Congresso Nacional Universidade, EAD e Software Livre, 2014. v. 2. p. 1-4

BOUHNIK, D., \& DESHEN, M. (2014). Whatsapp Goes TO School: Mobile Instant Messaging Between Teachers and Students. Journal of Information Technology Education: Research, 13, 217-231. Disp. em www. jite.org/documents/Vol13/JITEv13ResearchP217-231Bouhnik0601.pdf. Acesso em 15 de junho de 2015 .

BRANTES, J. ; SILVA, J. F. ; CAMPOS, H. ; CARVALHO, M. L. ; FREITAS A. ; SACCOL, Amarolinda Zanela; SCHLEMMER, Eliane ; KLEIN, Amarolinda Zanela. A disseminação da aprendizagem com mobilidade (M-learning). Datagramazero (Rio de Janeiro), v. 13, p. 1, 2012.

BROWN, J. Can you hear me now? Training and Development, 2010.pp 28-30.

CALVO, R., Arbiol, A., \& Iglesias, A. (2014). Are all chats suitable for learning purposes? A study of the required characteristics. Procedia Computer Science, 27, 251-260.Disp. em http://www.sciencedirect.com/science/article/ pii/S1877050914000301.Acesso em 15 de junho de 2015

CAUDILL, J. G. The growth of m-learning and the growth of mobile computing. International Review of Research in Open and Distance Learning, v. 8, n. 2, 2007. Disp.em http://files.eric.ed.gov/fulltext/EJ800950. pdf. Acesso em 15 de junho de 2015

COSTA, R. Tele-Experimentação Móvel (Mobile Remote Experimentation) Consideraçõessobre uma área emergente no ensino à distância. 2005. disponível em: <http://ave.dee.isep.ipp.pt/ rjc/Docs/2005/ NewsletterISEP2005/NewsLetterISEP.pdf >. Acesso em: 15 jun. 2015.

DUDENEY, G; HOCKLY, N. How to teach English with technology. Harlow: Longman, 2007.

EISENBERG, A. What did the professor say? Check your iPod. New York Times. 2007. Disponível em: http://www.nytimes.com/2007/12/09/ business/09novel.html?_r=0. Acessado em 10 de maio de. 2015.

GEDDES, S.J. Mobile learning in the 21st century: Benefit to learners. 2004 Disponivelem: $<$ http://knowledgetree.flexiblelearning.net.au/edition06/ download/geddes.pdf.> . Acessado em: 05 de mai. 2012

GEORGIEV, T.; GEORGIEVA, E.; SMRIKAROV, A. M-learning a new usage of eLearning. In: INTERNATIONAL CONFERENCE COMPUTER SYSTEMS ANDTECHNOLOGIES, 5. 2004, Rousse, Bulgaria. Proceedings. New York, USA, ACM, 2004. p. 1 - 5.Disponível em http://www.researchgate. net/publication/262367952 m-learning a new stage of e-learning. Acesso em 10 de junho de 2015

GOMES, C.; TOTTI, A. R.; SOUZA, W. G.; MOREIRA, S. P. T. M-learning: POSSIBILIDADES PARA A EDUCAÇÃO A DISTÂNCIA. In: $17^{\circ}$ Congresso Internacional ABED de Educação a Distância, 2011, Manaus. $17^{\circ}$ CIAED - Congresso Internacional ABED de Educação a Distância, 2011.

KALPAN A, Haenlein M. Users of the world, unite! The challenges and opportunities of social media. Business Horiz 2010; 53:59-68. Disp. em http://pt.slideshare.net/escpexchange/kaplan-haenlein-users-of-the-worldunite-the-challenges-and-opportunities-of-social-media. Acesso em 10 de junho de 2015

KEEGAN, D. (Org.) (2007). Mobile Learning: a practical guide, Disp. em http://www.ericsson.com/res/thecompany/docs/programs/incorporating mobile_learning_into_mainstream_education/book.pdf. Acesso em 08 de junho de 2015 .

KLEIN, A.; SCHLEMMER, Eliane; BARBOSA, Jorge Luis Victória; REINHARD, Nicolau. MLearning ou Aprendizagem com Mobilidade: um estudo exploratório sobre sua utilização no Brasil. In: XXX Encontro Nacional dos Programas de Pós-Graduação em Administração, 2007, Rio de Janeiro. ANPAD, 2007. v. 1. p. 1-17. Disponível em: https://gpedunisinos.files.wordpress.com/2009/06/art_m-learning-ouaprendizagem-com-mobilidade.pdf. Acesso em: 03 maios 2013.

KLEIN, Amarolinda Zanela.REINHARD, Nicolau . The Hospitality Metaphor as a theoretical lens for understanding the ICT adoption process. Journal of Information Technology, Oxford - Inglaterra, v. 21, n.3, p. 154164, 2006. Disponível em http://www.anpad.org.br/diversos/trabalhos EnANPAD/enanpad 2005/ADI/2005 ADIC1356.pdf. Acesso em 20 de maio de 2015 
KOSCHEMBAHR, C. Mobile Learning: the next evolution. Chief Learning Officer, February 2005.Disp. em http://www.clomedia.com/articles/mobile learning the next evolution of education. Acesso em 05 de junho de 2015 .

LAOURIS, Y. and Eteokleous, N. (2005). We Need an Educationally Relevant Definition of Mobile Learning. In: World Conference On Mlearning (m-Learn), 4. Cape Town, South Africa, Disp em http://www.mlearn.org.za/ CD/papers/Laouris\%20\&\%20Eteokleous.pdf. Acesso em 08 de junho de 2015 .

LEMOS, A. (2010). Celulares, funções pós-midiáticas, cidade e mobilidade. In: Urbe - Revista Brasileira de Gestão Urbana, 2, n. 2, p. 155-166.

MARÇAL, Edgar; ANDRADE, Rossana; RIOS, Riverson. Aprendizagem utilizando dispositivos móveis com sistemas de realidade virtual. Novas Tecnologias na Educação, Porto Alegre,V.3, N. 1, maio 2005. Disponível em:http://lumenagencia.com.br/dcr/arquivos/a51_realidadevirtual_revisado. pdf. Acesso em: 15 de junho de 2015.

MELO, R. S.; NEVES, B. G. B. Aplicativos Educacionais Livres para Mobile Learning. Revista Tecnologias na Educação, v. 6, p. 1, 2014.Disponível em http://www.periodicos.letras.ufmg.br/index.php/anais_linguagem tecnologia/article/view/5809/5098. Acesso em 10 de junho de 2015.

MIFSUD, L. Alternative Learning Arenas - Pedagogical Challenges to Mobile Learning Technology in Education. IEEE International Workshop on Wireless and Mobile Technologies in Education, Växjö, Sweden, 2002. Disponível em http://www.researchgate.net/publication/221229848_ Alternative Learning Arenas - Pedagogical Challenges to Mobile Learning_Technology_in_Education. Acesso em $\overline{0} 9$ de junho de $2 \overline{0} 15$.

MÜLBERT, A. L.; PEREIRA, Alice T. Cybis. Um panorama da pesquisa sobre aprendizagem móvel (m-learning). In: V Simpósio ABCiber 2011, 2011, Florianópolis. V Simpósio ABCiber 2011. Florianópolis: UFSC/ UDESC, 2011.

OLIVEIRA, E. D.S.; Medeiros, E.; Leite, J.E.R.; Anjos, E.G.; Oliveira, F.S. - Proposta de um modelo de cursos baseado em Mobile Learning: Um experimento com professores e tutores no WhatsApp. - ESUD 2014 - XI Congresso Brasileiro de Ensino Superior a Distância.

PACHLER, N., Bachmair, B. and Cook, J. (2010). Mobile Learning: Structures, Agency, Practices, New York, USA, Springer.

PECHI D. Como usar as redes sociais a favor da aprendizagem. Nova Escola 2011;6(246):1-4.Disponível em http://revistaescola.abril.com.br/formacao/ redes-sociais-ajudam-interacao-professores-alunos-645267.shtml. Acesso em 05 de junho de 2015.

PELISSOLI, L.; W. Aprendizado Móvel (M_learning): Dispositivos e Cenários. In: 3ra. Conferencia Iberoamerica en Sistemas, Cibernética e Informática, 2004, Orlando, Florida. Memorias. Orlando: International Institute of Informatics and Systemics, 2004. v. 1

PELISSOLI, Luciano; LOYOLLA, Waldomiro. Aprendizado Móvel (M-learning): Dispositivos e Cenários. In: Congresso Internacional de Educação a Distância - ABED, 11, Salvador: 2004.Disponível em http:// www.abed.org.br/congresso2004/por/htm/074-TC-C2.htm. Acesso em $04 \mathrm{de}$ junho de 2015.

PELLANDA, E. C. (2009). "Comunicação Móvel no Contexto Brasileiro", In: Comunicação e Mobilidade: aspectos socioculturais das tecnologias móveis de comunicação no Brasil, A. Lemos e F. Josgrilberg (Org.), Salvador, BA, EDUFBA, p. 11-18.Disponível em http://poscom.ufba.br/ arquivos/livro Comunicacao Mobilidade AndreLemos.pdf. Acesso em 20 de maio de 2015 .

PICONEZ, S. C. B. TecEduc@tion 2008 - 5o. Congresso de Tecnologia Educacional.M-learning (Mobile learning): novas fronteiras para $\mathrm{O}$ aprendizado escolar. 2008.Disponível em http://www.humus.com.br/news/ inovacao1.htm. Acesso em 20 de maio de 2015.

PRENSKY, M. (2010). Teaching Digital Natives: partnering for real learning, California, USA, Corwin Press.

PRETTO, Nelson De Luca e RICCIO, Nicia C. R. A formação continuada de professores universitários e as tecnologias digitais. Revista Educar. Curitiba, n. 37 , p. 153 - 169. Maio/agosto de 2010. Editora UFPR. Disponível em http://www.scielo.br/pdf/er/n37/a10n37. Acesso em 20 de maio de 2015.

REIS, R. S. F. WHATSAPP - UMA NOVA FERRAMENTA PARA O
ENSINO. In; IV Simpósio de Desenvolvimento, Tecnologias e Sociedade, 2014, Itajubá. MG. Anais do; IV Simpósio de Desenvolvimento, Tecnologias e Sociedade, 2014

SANTAELLA, L. (2008). A ecologia pluralista das mídias locativas. In: Revista FAMECOS, Porto Alegre: PUCRS, n. 37, p. 20 - 24, dez. Disponível em http://revistaseletronicas.pucrs.br/ojs/index.php/revistafamecos/article/ view/4795. Acesso em 10 de maio de 2015 .

SANTOS COSTA, Giselda dos. MOBILE LEARNING: Explorando potencialidades com o uso do celular no ensino - aprendizagem de língua inglesa como língua estrangeira com alunos da escola pública, Orientador: Antônio Carlos dos Santos Xavier. Doutorado em Letras. Universidade Federal de Pernambuco, UFPE, Brasil, 2013.

SARIOLA, J., Sampson, J., Vuorinen, R. and Kynäslahti, H. (2001). Promoting mLearning by the UniWap project within higher education. In: International Conference on Technology and Education, Florida State University, Tallahassee, USA, http://www.icte.org/T01 Library/T01 254. pdf, acesso em 10 de maio de 2015 .

SCHLEMMER, Eliane; Z.; Victória; Nicolau. M-learning ou aprendizagem com mobilidade: casos no contexto brasileiro. In: 13 Congresso Internacional de Educação a Distância, 2007, Curitiba. 13 Congresso Internacional de Educação a Distância. São Paulo - SP: Associação Brasileira de Educação a Distância - ABED, 2007. v. 1.

SCHOFIELD, C. P., West, T. and Taylor, E. (2011). Going Mobile in Executive Education: how mobile technologies are changing the executive learning landscape United Kingdom, Ashridge Business School, Disponível em https://uniconexed.org/2011/research/UNICON-Going_Mobile_In Executive_Education-Schofield-Taylor-West-Nov-2011.pdf. Acesso em 19 de maio de 2015

SHARMA, S. K., KITCHENS, Q. E. Web services model for mobile, distance and distributed learning using service-oriented architecture. International Journal of Mobile Communications, 2006. pp. 178-192.

SHARPLES, M., Arnedillo Sánchez, I., Milrad, M. and Vavoula, G. (2009). "Mobile Learning: small devices, big issues", In: TechnologyEnhanced Learning: principles and products, N. Balacheff, S. Ludvigsen, T. Jong, A. Lazonder, S. Barnes (Ed.), Netherlands: Springer, p. 233-249. Disponível em http://www.uio.no/studier/emner/matnat/ifi/INF5790/ v12/undervisningsmateriale/articles/KAL Legacy Mobile Learning (001143v1).pdf. Acesso em 05 de maio de $20 \overline{1} 5$.

SILVA, L. F.; OLIVEIRA, E. D.; BOLFE, M. Mobile Learning: Aprendizagem com mobilidade. Colloquium Exactarum, v. 06, p. 01, 2013.

SOUSA, M. A. O uso das redes sociais como ferramenta de ensino no IFCE Campus Quixadá. Encontro Nacional das Licenciaturas (5. 2014: Natal, RN). Professores em espaços de formação [recurso eletrônico]: mediações, práxis e saberes docentes / V Encontro Nacional das Licenciaturas, IV Seminário Nacional do Pibid. - Natal, RN: EDUFRN, 2014.

SOUZA, F. B.; JAMELLI, S.; MELO, M. M. D. C.; Carvalho; da; GOES P. A. Redes Sociais Virtuais como facilitadoras de aprendizagem na odontologia: opinião dos estudantes da universidade federal de Pernambuco. In: Cuba Saluda 2015 - Convención Internacional de Saluda Pública, 2015, Havana. Anais online da Cuba Saluda 2015 - Convención Internacional de Saluda Pública, 2015.

SOUZA, Maria C. C. Tecnologias avançadas e mudanças de paradigmas. Em: www.telecomuff.com disponível em, http://www.telecomuff.com/ uploads/6/9/4/8/6948141/uff_- tecnologias_avançadas_e_mudanças_de paradigmas - 2014 - sp.pdf, 23/06/2014

TAMMINEM, S.; OULASVIRTA, A.; TOISKALLIO, K.; KANKAINEN, A. Understanding mobile contexts. Personal and Ubiquitous Computing, 8: 135-143, 2004. Disponível em http://www.hiit.fi/u/oulasvir/scipubs/UMC Puc2004_Oulasvirta.pdf. Acesso em 05 de maio de 2015.

TAROUCO, L. M. R. et al.Objetos de Aprendizagem para M-learning. 2004. Disponível em: http://www.cinted.ufrgs.br/CESTA objetosdeaprendizagem sucesu.pdf. Acesso em: 23 de maio de 2015.

TOTTI, A. R.; MOREIRA, Simone de Paula Teodoro; SOUZA, Wanderson Gomes de; GOMES, C. M-learning: POSSIBILIDADES PARA A EDUCAÇÃO A DISTÂNCIA. In: $17^{\circ}$ Congresso Internacional ABED de Educação a Distância, 2011, Manaus. A Grande Conversação: Diferentes Formas de Aprender, Conteúdos Variados e Tecnologias Diferenciadas Interação com Diversidade, 2011 
TRAXLER, J. (2009). "Current State of Mobile Learning", In: Mobile learning: transforming the delivery of education and training, M. Ally, (Ed.), Canada, AU Press, p. 9-24.Disponível em https://www.academia.edu/180449/ Current_State_of_Mobile_Learning. Acesso em 05 de maio de 2015.

TRAXLER, J. Defining, discussing and evaluating mobile learning: The moving finger writes and having writ. IN: The International Review of Research in Open andDistance Learning. 2007. . Disponível em: http:// www.irrodl.org/index.php/irrodl/article/view/346. Disponível em http:// www.irrodl.org/index.php/irrodl/article/view/346/875 Acesso em 15 de maio de 2015.

UNESCO. Policy Guidelines for Mobile LearningDisponível em: http:// unesdoc.unesco.org/images/0021/002196/219641E.pdf. Acesso em: 10 de maio de 2015.

UNIVERSITÄT SIEGEN, Corvinus University of Budapest, Empirica, Oxford Internet Institute, University of Twente (2010). Work Research Centre, Study on the Social Impact of ICT, Final Report. Brussels: European Commission. http://ec.europa.eu/information_society/eeurope/i2010/docs/ eda/social_impact_of_ict_exec_sum.pdf, Acesso em 10 de maio de 2015.

VALENTIM, H. Para uma Compreensão do Mobile Learning: Reflexão sobre autilidade das tecnologias móveis na aprendizagem informal e para a construção deambientes pessoais de aprendizagem. Lisboa. Dissertação de Mestrado. 2009. Disponível em: http://hugovalentim.com/sites/default/ files/Hugo_Valentim_M-learning.pdf. Acesso em: 12 de janeiro de 2014.

VEEN, W., Vrakking, B. (2009). Homo Zappiens: Educando na era digital, Porto Alegre: Artmed. Disponível em www.ucs.br/etc/revistas/index.php/ conjectura/article/download/.../286. Acesso em 01 de maio de 2015. 